\title{
Mediações na atenção à saúde sob a ótica da Teoria da Dádiva: a saúde da população rural em destaque
}

| ${ }^{1}$ Eliziane N. F. Ruiz, ${ }^{2}$ Vilma Fioravante dos Santos, ${ }^{3}$ Tatiana Engel Gerhardt I

Resumo: Objetivou-se analisar, sob a perspectiva da Teoria da Dádiva, as implicaçôes da mediação realizada pelos profissionais da saúde entre o usuário rural e as Políticas de Saúde. O estudo foi conduzido sob abordagem qualitativa, com produção de dados por entrevistas e observação participante com profissionais, usuários rurais e gestores do SUS de dois municípios do Rio Grande do Sul. Verificou-se que a mediação se mostra como uma possibilidade de os profissionais produzirem saúde, excedendo os limites técnicos e biomédicos, ao se estabelecer relações mais simétricas com os usuários e se exercitar a capacidade de compreender as especificidades da vida e valores rurais. Esses elementos fomentaram a circulação de materialidades e imaterialidades que têm a potência de produzir afeto, cidadania e solidariedade enquanto bens de saúde. Contudo, constatou-se que estigmas em relação ao modo de vida rural interferem na forma como os profissionais atuam junto aos usuários, fazendo de suas necessidades, por vezes, um evento redutível à tutela profissional, que mais exclui e dificulta o acesso aos serviços de saúde do que produz cuidado. Por fim, entende-se que problematizar a vida rural é ímpar para que as ações em saúde tenham êxito.

> Palavras-chave: população rural; mediação em saúde; dádiva.

\author{
1 Programa de Pós-Graduação \\ em Desenvolvimento Rural, \\ Universidade Federal do Rio \\ Grande do Sul. Porto Alegre-RS \\ Brasil (elizianeruiz@yahoo. \\ com.br) \\ 2 Faculdade de Enfermagem, \\ Universidade Federal do Rio \\ Grande do Sul. Porto Alegre-RS, \\ Brasil (vilma.santos@ufrgs.br). \\ ${ }^{3}$ Programa de Pós-Graduação \\ em Desenvolvimento Rural e \\ Programa de Pós-Graduação em \\ Saúde Coletiva, Universidade \\ Federal do Rio Grande do Sul. \\ Porto Alegre-RS, Brasil (tatiana. \\ gerhardt@ufrgs.br).
}

Recebido em: 11/05/2015 Aprovado em: 22/04/2016 
Muito se tem discutido sobre uma "nova ruralidade" (WANDERLEY, 2000; 2004; 2009; VEIGA, 2004) marcada pela capacidade do rural em se (re)colocar enquanto espaço privilegiado de vida, para além da sua competência produtiva. No entanto, ao nos determos mais atentamente no cenário rural do Brasil, de forma geral, é possível observar ainda um quadro de inequidades e características que, em certa medida, marcam esse espaço.

As inequidades que marcam o rural são reflexos de nossas especificidades sóciohistóricas e políticas de períodos distantes e também não tão distantes. Dentre elas, destacam-se os fatos de que as definições e ações político-administrativas são exercidas a partir de uma lógica do urbano e que, de forma centralizada e desfocada, concentram as decisóes e a oferta de serviços públicos/privados (WANDERLEY, 2004). Historicamente, o rural brasileiro está marcado por políticas de desenvolvimento que privilegiaram a exploração de recursos naturais e a modernização do setor agrícola, calcadas no uso extensivo de produtos químicos e incentivo financeiro para grandes produtores (WANDERLEY, 2004; LERRY, 2002). Nesse contexto, o homem e a mulher do campo tiveram de renunciar a seus saberes tradicionais e se apropriar de um novo saber, no intuito de serem eficientes na agricultura moderna, embora perdessem com isso sua identidade e tivessem sua inserção não completa na modernidade. Paralelamente, o urbano é idealizado como a única possibilidade de concretizar a modernidade, uma vez que lá se concentram elementos como a indústria, os postos de trabalho, os melhores salários e o modo de vida que se opõe ao tradicional (MARTINS, 2011).

O rural era visto, nesse cenário, como uma das causas da estagnação brasileira perante as nações mais desenvolvidas. A inferioridade dos saberes tradicionais e da diversidade rural frente ao moderno da revolução verde era a própria causa do abandono dessas pessoas, que perdurou por muitas décadas (ESCOREL; TEIXEIRA, 2008). Assim, o Brasil, no seu processo de modernização valorizou mais o urbano e a economia industrial e exportadora, do que rural com sua gente. Somado a isso, as informaçôes oficiais (IBGE, 2011) mostram um aumento do grau de urbanização do país, que passou de 81,2\% em 2000, para 84,4\% em 2010. No entanto, essa análise desconsidera alguns indicativos de que até um quarto da população do Brasil pertence a municípios com menos de 50 mil habitantes, com baixa densidade populacional, e que, ao preservarem características rurais, 
poderiam ser considerados mais rurais do que urbanos (VALADARES, 2014).

Isso tudo demonstra certa valorização da dimensão urbana do Brasil e uma desvalorização e invisibilidade do rural enquanto parte da sociedade, onde vidas, com suas necessidades, habitam e a ele dão um formato.

É pertinente reconhecer que a comida que alimenta o urbano no Brasil, até hoje, vem dos pequenos agricultores, e que ao se priorizar apenas a agricultura exportadora de grãos nega-se a contribuição do campesinato para a sociedade (WANDERLEY, 2014). Em outros termos, o rural brasileiro ofereceu muito mais do que recebeu; foi mais explorado enquanto lugar que ganha visibilidade por ser produtor de capital do que tido enquanto espaço também de vidas e merecedor de retorno social e político (LERRY, 2002).

A história das políticas públicas no Brasil demonstra que a população rural teve seus direitos trabalhistas reconhecidos muito tardiamente, assim como seu direito à assistência à saúde (ESCOREL; TEIXEIRA, 2008). A possibilidade de a população rural ter acesso a serviços estava atrelada ao reconhecimento da legitimidade da ocupação de trabalhador rural, que se deu somente na década de 1970, no modelo de Programa de Assistência ao Trabalhador Rural (BRASIL, 1971). Porém, o acesso à saúde enquanto direito, independentemente da contribuição sindical, deu-se somente com a criação do Sistema Único de Saúde (SUS), no final da década de 1980, e foi intensificado com investimentos na Atenção Primária em Saúde e nas Equipes de Saúde da Família (ESF). A Atenção Primária configura possibilidade de reorientação do modelo assistencial na América Latina, voltando-se para outras formas de oferecer atenção em saúde, mais próximas às pessoas e coerentes com os modos de vida de seus usuários, inclusive o usuário rural (BRASIL, 2012; TOVAR-CUEVAS; ARRIVILLAGAQUINTERO, 2014).

Contudo, para apreender a situação e as necessidades de saúde dessa população, não bastam indicadores epidemiológicos ou sociais tradicionais, como aqueles que partem de uma lógica que, por exemplo, tenta demonstrar a relação direta entre o acesso às políticas e a superação dos problemas de saúde. Os problemas de saúde do rural, demonstrados em dados epidemiológicos, não são tão diversos aos do urbano (BARROS et al., 2006). Claro que há especificidades importantes no rural, como as intoxicações por agrotóxicos e os agravos causados pelas condições mais precárias de trabalho (SOBREIRA; ADISSI, 2003; RIQUINHO; 
HENNINGTON, 2014). No entanto, as especificidades do rural para as quais queremos chamar a atenção são de outra ordem.

Para avançar nessa discussão sobre as necessidades em saúde no rural, sugerese considerar também outros elementos e os aspectos mais subjacentes a cada realidade em questão e aos seus modos de viver. Em outros termos, é necessário atentar para a forma com que os atores sociais constroem suas identidades e, consequentemente, suas necessidades e experiências de adoecimento, e as têm reconhecidas pelas políticas e serviços de saúde locais (ALMEIDA FILHO, 1999; SANTOS; GERHARDT, 2008; RIQUINHO, 2009; GERHARDT; LOPES, 2015). Algumas experiências e dados produzidos por pesquisas no meio rural vêm demonstrando que, até mesmo quando o acesso a bens e aos serviços (como os de saúde) não está longe de ocorrer, há questôes que não são compreendidas ou ficam desassistidas (RIQUINHO, 2009; RUIZ; GERHARDT, 2012).

A exemplo disto, Riquinho e Gerhardt (2010) demonstram que tão importante quanto agricultores familiares serem reconhecidos como portadores ou não de uma patologia é serem reconhecidos como pessoas que dependem do trabalho na terra e têm nele sua marca. As lidas com a terra, portanto, parecem atuar tanto na manutenção material da família quanto na produção da identidade e intersubjetividades da gente do rural. Assim, parece ser fundamental compreender o meio rural e suas especificidades, ou seja, compreender a forma com que a saúde e a doença interferem na vida ou, por outro lado, como o cotidiano rural, o vivido pelas pessoas em suas interações, influencia no processo de construção das necessidades e soluções em saúde, da doença e do ser "doente".

Desconsiderar a dinamicidade da vida, no caso rural, tende a interferir negativamente, como discute Martins (2008), tanto nos avanços no SUS como no planejamento de ações de saúde e empoderamento dos atores sociais, usuários, que compõem esse cenário. O que esse autor sugere para o sucesso do SUS é que possamos repensar a saúde-doença-cuidado como um fenômeno social e cultural não restrito às intervençôes técnicas, mas como algo produzido e compartilhado nos microespaços onde o sistema de saúde encontra o mundo da vida.

Nesse sentido, uma estratégia interessante para se analisar as necessidades, os problemas e as soluções em saúde parece ser olhar para o que emerge dos encontros entre a população rural (o usuário que demanda a atenção em saúde) e o Estado, que acaba agindo como interventor nos cenários de vulnerabilidades 
e invisibilidades do rural como espaço não só produtivo, mas espaço de vida e de modos de vida (RUIZ; GERHARDT, 2012). Contudo, na busca por ir mais a fundo nessa junção vida rural-Estado e o que emerge dela em termos de saúde, propõe-se como essencial compreender o papel que desempenham os profissionais de saúde, que podem ser considerados mediadores das políticas/ ações (MARTINS, 2008). Nesse sentido, o mediador (profissional/trabalhador da saúde) seria a via pela qual, concretamente, o Estado, no microespaço, interage com o usuário, fazendo circular os bens das políticas (serviços, medicamentos, recursos materiais, afetos e escuta etc.). Bens que podem ser considerados de cuidado e que seriam, então, dependentes da forma como o profissional se coloca para mediar o encontro, ou seja, fazer a mediação entre o usuário e a política de saúde (PINHEIRO; MARTINS, 2011).

Portanto, a mediação em saúde realizada pelo profissional, ao ser considerada um espaço através do qual a lógica estatal se comunica com lógica comunitária, seria capaz de abrir caminho para o "exercício de uma sabedoria prática para a saúde, apoiado na tecnologia, mas sem deixar de resumir-se a ela" (AYRES, 2004, p. 86). Ou seja, aposta-se que o profissional, pela mediação e a cada novo encontro em que o outro rural com suas necessidades torna-se o centro da ação, tem potencial para exercitar atitudes cuidadoras e apoiadoras do êxito do SUS. Com isso, defende-se que a mediação, nos termos da teoria da Dádiva - de que trataremos mais adiante -, ao ser fruto de encontros e produtora de desfechos, teria implicaçōes para todos os envolvidos na ação: quem doa, quem recebe e retribui os bens das políticas em saúde.

A partir do exposto, o que se pretende com este trabalho é analisar, sob a perspectiva da Teoria da Dádiva, de Marcel Mauss (MAUSS, 2003), experiências de profissionais de saúde do SUS que atuam em contextos rurais, visando, com isso, contribuir com elementos para o debate sobre o potencial desses atores, ao engendrar encontros mais amistosos/humanizados com os usuários, produzir inovações em saúde para a população rural.

Para expor o trabalho, primeiramente, apresentar-se-á a dádiva em seu arcabouço teórico e em sua contribuição para analisar a relação do profissional com o usuário do SUS e as implicações desse encontro; em seguida, serão expostos os caminhos metodológicos da pesquisa. Nos resultados, serão explorados alguns aspectos das experiências de mediação dos profissionais junto a usuários do rural: 
a) os cenários de mediação e o papel dos profissionais como mediadores; b) as expressões da mediação e as implicações dos encontros para ambos os envolvidos e seu entorno; e c) os desafios colocados à atuação profissional produtora de saúde. Por fim, serão realizadas considerações que possam alargar o debate sobre a importância da relação profissional-usuário na concretização das ações produtoras de saúde rural.

\section{A Dádiva como um referencial teórico para apreender encontros no SUS}

Os motivos que movem o estabelecimento de relações entre os sujeitos foram sistematizados por Marcel Mauss na forma da Teoria da Dádiva (MAUSS, 2003). Para o autor, a dádiva consiste num conjunto de prestaçôes e contraprestações que ocorrem mediante um ciclo marcado pela obrigação (e liberdade) em se doar, receber e retribuir bens materiais ou imateriais que agem na formação do coletivo e dos indivíduos (CAILLÉ, 2002; GODBOUT, 1997; MARTINS, 2005). Partindo da leitura de Mauss (2003), seriam dádivas não só os presentes, como também tributos, medicamentos, alimentos, visitas e um sem número de prestações. Nesse sentido, tudo que circula em torno das relações seria importante para esclarecer sua origem e funcionamento.

Mauss propõe com sua teoria uma nova leitura dos sistemas sociais, defendendo que a ação humana não poderia ser reduzida às motivações nem puramente econômicas, nem políticas, e/ou culturais. Ele apontou a relevância e pluralidade de todos esses motivos e de diversas dimensões envolvidas nos encontros do social: o material e imaterial, interesses individuais e grupais, liberdade e obrigação em seguir normas; ou seja, há articulação entre dicotomias no seio de prestações e contraprestações. Inclusive, o autor destaca a dimensão simbólica dos bens. Acima de bens e do interesse material o que circula nos encontros são símbolos, o "espírito da coisa", ou seja, a intenção oferecida conjuntamente com o dom (MAUSS, 2003).

Ultimamente, a concepção da dádiva tem sido revisitada e difundida por diversos autores como Alain Caillé (2002), que chega a sustentar que o dom seria um terceiro paradigma: uma teoria mais maleável, que permite articular elementos dos dois outros paradigmas. Isto é, a dádiva como teoria social não se forma a partir da exclusão dos elementos fundamentais das outras duas 
grandes vertentes teóricas: a) o utilitarismo (ou individualismo) - que regeria

o mercado e considera que os indivíduos são movidos pela racionalidade, interesse individual e utilidade na busca incessante de ganhos; e b) o holismo que regeria o Estado e que sugere que a natureza da ação social se dá em função da obrigação com leis e normas.

$\mathrm{O}$ que os autores têm discutido é a incapacidade de tais teorias em pensar as instituições, como o Estado, como sendo provenientes das interações humanas, não só no plano microssocial, mas também em uma perspectiva mais macrossociológica das organizações formais (CAILLÉ, 2002; MARTINS, 2005; GODBOUT, 1997).

Para Godbout (1997), a dádiva é capaz de ocorrer em todos os planos onde existem sociabilidades. A dádiva na forma de bens doados-recebidos-retribuídos dá suporte ao funcionamento das instituiçôes sociais. Sem relações entre pessoas e, possivelmente, sem comunicação e confiança, nem o Estado, com suas leis e políticas públicas, nem tampouco o mercado, em sua abstrata norma da oferta e da procura, se sustentariam.

Enfim, com base nesse panorama da Teoria da Dádiva, cabe registrar quais sejam, talvez, suas maiores contribuições para a apreensão dos encontros entre profissionais e usuários em seu potencial produtor de saúde rural. Considerando que os bens das políticas que chegam aos usuários rurais são carregados de um espírito (simbolismo/imaterialidade), com eles podem vir junto boas ou más intenções. Assim, surge o interesse em olhar a forma com que o profissional mediador manipula os bens, que seriam de cidadania (RUIZ; GERHARDT, 2012), quando possibilitam, ao usuário rural, o acesso à política de saúde.

Por último, interessa chamar a atenção para o fato de que, ao discutir a dádiva como um sistema que se movimenta num ciclo composto pela tríade dar-receberretribuir bens, Mauss extrapola a ideia de relação, como a do profissional e usuário, como sendo uma troca. Apreciar a dádiva como uma troca seria fixar o olhar em parte do movimento: no dar-receber ou dar-retribuir, tratando-a como uma mercadoria de saúde na lógica da equivalência entre pares (LACERDA, 2010). Isso sugere que avancemos da díade para um modelo analítico triádico. Assim, até mesmo o encontro entre duas pessoas nos serviços de saúde, possivelmente, terá reflexos para além delas. Nesse sentido, no momento em que o SUS, pela via do mediador, assume retribuir atendendo demandas sociais, ele estaria 
alimentando a possibilidade, inclusive, da construção de uma sociedade e de um Estado mais comprometidos com a saúde. Ou seja, uma dádiva do Estado/ profissional para o usuário pode ter como desdobramento civismo e participação deste no Estado e no cuidado de si, assim como solidariedades dos usuários com suas redes. Além disso, há a possibilidade de criar vínculos mais intensos do usuário com o profissional, considerando o reconhecimento que o profissional passaria a ter, pois, ao situar quem doa na posição de possível receptor, a dádiva possibilita que o profissional também seja afetado pelo usuário e possa afetar seu entorno nos serviços de saúde.

Enfim, a importância da utilização da Teoria da Dádiva como referencial está na aposta do potencial do fato associativo, da participação e inventividade dos profissionais e usuários na concretização de políticas no cotidiano e na construção de uma sociedade mais solidária e responsável com o bem comum que é a saúde (CHANIAL, 2001; MARTINS, 2005).

\section{Recompondo o caminho do estudo}

Este é um estudo qualitativo de cunho etnográfico; o percurso para construir a discussão aqui apresentada ocorreu a partir de fundamentos teóricos e empíricos produzidos em dissertação (SANTOS, 2013) e tese (RUIZ, 2013) no âmbito de um projeto de pesquisa intitulado "Gestão em saúde e usos do território: fluxos de utilização dos serviços de saúde e mobilidade dos usuários por Condições Sensíveis a Atenção Primária”, com aprovação pelo Comitê de Ética da Universidade Federal do Rio Grande do Sul (CEP/UFRGS), sob o número 20494.

Para expor as experiências de mediação, ou seja, encontros entre profissionais e usuários na atenção à saúde rural, fomos buscar dados que tiveram como pano de fundo dois contextos que oferecem cenários profícuos para o debate das questôes aqui analisadas. Os dois municípios em estudo, São Lourenço do Sul e Canguçu (Rio Grande do Sul), têm considerável parcela de pessoas vivendo no rural: 44\% (18.968 habitantes) e 65,60\% (33.742 habitantes) da população, respectivamente. Ambos os municípios têm como característica em comum uma agricultura familiar instalada em pequenos estabelecimentos agrícolas com produção frutífera e de fumo. O diferencial desses cenários, na época da pesquisa de campo, foi que, enquanto São Lourenço do Sul dispunha de Atenção Básica (AB) instalada no território rural por meio da inserção física das equipes de ESF, 
que seria a porta de entrada no sistema de saúde, Canguçu, não apresentava cobertura instalada e contínua desse tipo atenção no território rural.

Os dados foram produzidos entre janeiro e agosto de 2012 a partir de: a) entrevistas semiestruturadas com 10 adoecidos crônicos adultos e idosos rurais (6 mulheres e 4 homens) e 12 profissionais de saúde que atuam no atendimento à população rural nos municípios; e b) observação participante junto ao cotidiano dos adoecidos rurais e de serviços de saúde da atenção básica.

Quanto ao número de participantes, cabe pontuar que, nas abordagens qualitativas, os processos de quantificação são relativamente secundários, tendo em vista que um dos seus objetivos é procurar compreender os meandros do contexto e das relações sociais na sua amplitude, essência e profundidade (MINAYO, 2008). Desse modo, na definição dos participantes, não buscamos uma representatividade numérica, mas um aprofundamento da temática estudada. Os dados foram organizados e analisados a partir da categorização temática proposta por Minayo (2008), seguindo a pré-análise (organização do material e composição de núcleos centrais); exploração do material (codificação); tratamento dos resultados obtidos e interpretação à luz da Teoria da Dádiva.

\section{Os cenários da mediação e os modos de mediar a produção da saúde rural}

A oferta de ESF está relacionada à expectativa de que o acesso ao sistema de saúde se dê de maneira mais facilitada e organizada, além do atendimento no próprio território. Em se tratando do rural, em específico das realidades estudadas, um elemento que se mostrou importante para a análise diz respeito ao fato de que ambos os municípios, mesmo sendo diferentes quanto à oferta de ESF/AB, compartilham de fluxos muito semelhantes no que diz respeito ao deslocamento das pessoas que vivem no rural para o urbano na busca por atendimento em saúde. No município em estudo sem ESF instalada no rural, os usuários buscavam serviços no urbano, principalmente em função do vazio assistencial instalado (RUIZ, 2013). Por sua vez, no município com ESF instalada, houve relatos dos profissionais de que as pessoas se deslocavam até o urbano para receber atendimento, mesmo havendo pessoal para atendê-las (SANTOS, 2013), como ilustra um profissional que trabalha no urbano: 

lá... E aí a pessoa resolve fazer um pagamento e passa por aqui [...]. Por que não foi procurar lá primeiro [rural]? Aí que eu te pergunto, por que não foi lá? E veio direto para o Pronto Socorro? [no urbano] (Iris, profissional enfermeiro que atua no urbano)

O deslocamento do usuário aponta para aspectos mais amplos do cotidiano dos serviços de saúde; aspectos da ordem de relações mais horizontais entre profissionais/Sistema de Saúde e das pessoas que vivem no rural. Nesse sentido, as distâncias não são unicamente da ordem geográfica, elas dizem respeito às dificuldades dos profissionais em estabelecer relações com os usuários, capazes de reconhecer, valorizar e incorporar em suas açôes as identidades e particularidades conformadas no rural (SANTOS; GERHARDT, 2016). Os usuários valorizam, além da disponibilidade de serviços no território, a disponibilidade e presteza com que os profissionais os atendem (OLIVEIRA et al., 2015).

A partir desse panorama, apreende-se que, mesmo que a expansão do quantitativo de AB/ESF tenha favorecido a universalidade da assistência em espaços onde anteriormente o acesso físico ao serviço era mais restrito, isoladamente, essas estratégias não garantem a construção de um novo modelo assistencial em saúde. Para isso, seria fundamental o desenvolvimento de novas racionalidades em saúde (ALVES, 2005), que aproximem não só as distâncias geográficas, mas também as distâncias entre as racionalidades que regem o encontro entre o profissional e os usuários.

No campo do direito à saúde, muitos foram os ganhos no que concerne ao reconhecimento da população rural perante as políticas públicas. Entretanto, isso não garante que esses direitos sejam alcançados em sua plenitude. Mesmo que não haja muitos estudos que analisem o acesso aos serviços de saúde no rural (TOVAR-CUEVAS; ARRIVILLAGA-QUINTERO, 2014), verifica-se que ainda persistem vazios assistenciais e, também, grandes distâncias a serem percorridas pelas equipes e usuários na busca pela oferta e acesso aos serviços de saúde (OLIVEIRA et al., 2015; GALVÃO et al., 2015; UCHOA et al., 2011; PERETTO et al., 2011). No rural brasileiro, o modelo campanhista de atendimento em saúde ainda perdura; as equipes de saúde deslocam-se do urbano para o rural de acordo com agendas pré-estabelecidas e com periodicidade que pode variar de uma a duas vezes por mês, no formato de equipes móveis (BURILLE; GERHARDT, 2014). Em estudo na Metade Sul do Rio Grande do Sul, foi verificado que a lógica de atendimento de determinados agravos, como 
a violência, segue um "roteiro de atendimento" segundo o qual o adoecimento

precisa ter hora ou momento certo para acometer esta população, ou seja, é preciso ter "sorte" em ser atendido (COSTA, 2012, p.195).

Nas situações pesquisadas, o que estaria em jogo, em ambos os municípios, é a oportunidade de o usuário rural ter suas necessidades levadas em conta em algum serviço, seja ele $\mathrm{AB}$ ou outro âmbito de atenção. A não escuta do modo de vida rural, motivada pelas características próprias da assistência e da lógica de trabalho do profissional, simplesmente não favorece o cuidado. As entrevistas com alguns profissionais retrataram a não compreensão da relação entre cuidado, acesso aos serviços e a rotina das famílias que está ligada à especificidade do trabalho com as lavouras e as suas temporalidades regidas pela natureza: o plantar e colher o fumo dependem do sol, da chuva e da época do ano. A transcrição a seguir denota a dificuldade em entender o trabalho com a terra e com a natureza como elemento de mediação no cuidado:

[...] não fecha com os horários deles de trabalho, eles não largam a lavoura, eles não acham que a saúde é em primeiro lugar! Para eles não! Não é! E primeiro lugar é a lavoura, é o dinheiro [...] (Hortência - profissional médico que já atou em uma das ESF do rural).

Essa fala vai de encontro com a realidade dos nossos interlocutores, na sua maioria plantadores de fumo que convivem, além das imposiçōes da natureza, também com imposições e dívidas junto às empresas fumageiras; caso deixem de cumprir com seu trabalho, podem ter perdas materiais e imateriais irreparáveis. Isso é o reflexo da produção rural atual que, mesmo proveniente da agricultura familiar, parece atender, cada vez mais, à lógica industrial e de sua necessidade de recursos, bem como da lógica das políticas de investimento no campo. Dessa forma, percebe-se que, a partir das especificidades partilhadas por ambos os municípios (como os fluxos de utilização que se assemelham e a postura dos profissionais, que se afastam de relações horizontais com os usuários), justifica-se a análise dos microespaços de atenção em saúde, tal como ensejamos com este trabalho.

Nesse sentido, há de se destacar que foram os microespaços dos grupos de promoção da saúde e das visitas domiciliares da $\mathrm{AB}$ e, principalmente, das ESF rurais, que se sobressaíram enquanto possibilidades privilegiadas para a produção da saúde. Não que em outros espaços a mediação produtora de saúde não ocorra, mas esses cenários mostraram-se ímpares ao possibilitarem ao profissional se deslocar da normatividade técnica, se expressar mais livremente no encontro 
com o mundo da vida do outro rural e potencializar afetamentos capazes de movimentar de forma mais solidária e humana um sistema de saúde muito maior do que é explícito pelas políticas públicas.

Analisando o papel do profissional, observamos que esses atores são capazes de produzir saúde, em sentido amplo, na medida em que, na sua ação de mediação, aparecem elementos de alteridade, ou seja, a capacidade de apreender e respeitar um outro rural na plenitude da sua dignidade, dos seus direitos e, principalmente, da sua diferença. Esses elementos demonstram a capacidade justamente de realizar deslocamentos, afetando o usuário e se deixando afetar por ele, conforme descreve um profissional.

[...] vem da convivência, do carinho, da compreensão, porque muitas vezes assim ó, não adianta, tu tens algum problema. - Ah, paguei, deu! Ah, está pago, agora que se vire. Não funciona assim, tu tens que ter... Não sei explicar... Como agir, por isso que eu digo, cada ser humano é um ser humano, tu trabalhas com pessoas, eu tento dar sempre o melhor de mim, o melhor possível, tento ajudar, tento escutar, compreender. (Flor de Lótus, profissional Técnico em Enfermagem).

A partir desse relato, acreditamos que a capacidade do serviço em acolher as demandas vai para além da sua disponibilidade em termos do acesso geográfico ao usuário e do cuidado técnico realizado. Acolher demandas depende do modo como o profissional se coloca mediando encontros dos usuários com as políticas, dando, recebendo e retribuindo dádivas. Os encontros podem ser percebidos como momentos de trocas entre os sujeitos, reconhecimento das diferenças enquanto riquezas, compartilhamento de responsabilidades no cuidado e cidadania. $\mathrm{Ou}$, de outro lado, um evento redutível ao oferecimento de um repertório técnico e de tutela profissional que mais exclui e torna o usuário vulnerável do que inclui ao doar assistência(lismos) aos "sem" renda e acesso aos serviços e "sem" esclarecimentos (por estarem longe do urbano e por isso “isolados"), como ouvimos de alguns profissionais referindo-se à população rural.

\section{Expressões e implicações da mediação produtora da saúde rural}

Ao buscar apreender a mediação como o encontro entre o Estado e o usuário em que o profissional se coloca como mediador na produção da saúde, partimos do entendimento de que nesses encontros há circulação de dádivas, isto é, “doaçôes de visibilidade e dignidade que é o dom do reconhecimento, gerando 
agradecimentos, inclusōes e participaçōes”, como lembra Martins (2011, p. 47).

Assim, quando partimos para entender as formas de expressão e a implicação da mediação que faz circular dádivas e é capaz de produzir saúde, nos deparamos com Honneth (2003), quando discute que a integridade humana se deve ao recebimento do reconhecimento que surge das respostas das outras pessoas à nossa presença. Com base na fenomenologia de Hegel e na psicologia social de George Mead, esse autor expõe três dimensões distintas de reconhecimento que, tomadas em conjunto, seriam consideradas dádivas imprescindíveis na constituição do usuário e na produção da sua saúde: a) a dimensão do afeto, que gera autoconfiança; b) a dimensão das leis e direitos, que gera autorrespeito; e c) a dimensão da solidariedade, que implica autoestima.

No que se refere ao reconhecimento na forma de afeto, o percebemos como um bem de cuidado que os profissionais foram capazes de expressar de diferentes formas, não necessariamente no contato físico, mas na presença e atitudes, nas palavras, na escuta e, principalmente, no respeito ao adoecido na sua condição e valores rurais.

Como ilustração do afeto, da atitude de apreço por alguém, que circula nos encontros entre profissional e usuário, trazemos para o texto o relato de uma de nossas interlocutoras, Tulipa, que nos confidencia que, mesmo tendo que ser hospitalizada em função de uma complicação de seu diabetes, não tinha achado ruim. Isso porque dela não foi exigido que deixasse de lado o valor das relações de proximidade praticada junto à família e que são tão caras e representam as pessoas dos contextos rurais do nosso estudo. Tulipa comenta:

\footnotetext{
Não é tão ruim sabe por quê? Porque onde eu estou tem família. As gurias lá [no hospital] eram uns amores comigo. Para me tratar. -Tulipa vamos lá, Tulipa vamos isso e vamos aquilo, e vamos lá. Eu brincava com elas também, né?! Não ficava quieta, né?! E elas me amavam, elas gostavam de estar lá, me ajudavam [...] (Tulipa, agricultora e usuária do SUS).
}

Percebemos que há um apreço importante pela família no rural que investigamos. A rede familiar, mesmo unindo as pessoas em torno de algumas obrigaçōes, é central, pois, além de viabilizar apoio, cumpre uma função de base na organização das formas de se viver e enfrentar o cotidiano. Família (assim como o trabalho) é importante pois é um dos sustentáculos da ética e dos valores camponeses, como hierarquia, reciprocidade e honra. A importância da família e dos valores que elas representam aparecem em algumas situações observadas por 
nós na realização das nossas pesquisas. Uma de nossas interlocutoras exemplifica na sua fala o quanto a família é central:

[...] se eu tenho, assim, um filho que está com problemas eu também estou porque é minha carne também. Se o meu marido está, também, né? Se a minha mãe está, também. Se um irmão meu está, também (Rosa, agricultora e usuária do SUS).

Ao participarmos dos encontros entre familiares ou presenciarmos conversas ao telefone, os mais novos pediam e recebiam a bênção dos mais velhos ou superiores em termos geracionais, sendo os últimos tratados como senhor e senhora. Desse modo, a partir da fala da Dona Rosa e dos cumprimentos, foi possível abrir janelas para analisar alguns valores aí embutidos (obrigação, hierarquia, reciprocidade e respeito) (RUIZ, 2013).

A partir da experiência supracitada de Tulipa (agricultura), a dádiva, na forma de afeto, ao contrário do que alguns autores sugerem (GODBOUT, 1997), mostra penetrar também na esfera do Estado. Nesse sentido, uma relação que poderia ser orientada apenas em função do acometimento de uma enfermidade no corpo biológico, a ser tratada com medicamentos e aparelhos, toma rumos em que as pessoas estão no centro. Não só o biológico e a técnica, com sua normatividade, regulam a relação, mas dádivas que se dão no momento do encontro e possibilitam recriações. Ao adoecido, abre-se uma lacuna para se perceber não mais sendo destituído de si, o que seria típico de se esperar da atenção hospitalar, mas autoconfiante enquanto pessoa que, com seus valores, merece atenção e, por isso, é também capaz de se colocar a participar do cuidado.

Ao partirmos para a análise das doações de reconhecimento pela segunda via da integridade, a do direito, a mediação produtora de saúde pareceu se efetivar quando, dos encontros entre profissionais e usuários, surgiu a possibilidade de superar tanto a concepção reduzida da saúde como ausência de doenças quanto a concepção de direito à saúde que se resuma à oferta de serviços e medicamentos destituída da participação do usuário.

Para ilustrar tal apreensão, trazemos o relato de Gardênia, profissional nutricionista que trabalha com grupos de adoecidos crônicos organizados junto à atenção primária em saúde em Canguçu. Nas palavras dela, as pessoas "davam muita importância para medicação, mas eu comecei a tentar a fazer eles entenderem que, para tirar remédios, se tira em qualquer lugar [...]" (Gardênia, profissional nutricionista da $\mathrm{AB})$. 
$\mathrm{Na}$ sua fala, ao expressar que o objetivo do grupo não seria apenas retirar o medicamento de uso contínuo, Gardênia acaba demonstrando outras atitudes prováveis na condução da política pública. Há um entendimento e uma abertura desse espaço, mesmo que ainda incipiente, no sentido de realizar o acesso e permitir ao usuário dar visibilidade à sua identidade, e não somente à sua doença, podendo, com isso, perceber-se respeitado enquanto cidadão que tem direitos e participa.

O mesmo profissional relata que procura, quando possível, abordar assuntos que possam ir ao encontro das necessidades sociais e do perfil dos participantes, que são, na maioria, do rural e agricultores. Ele exemplifica que, em certo mês, conversou com o grupo sobre as novas bases legais do Ministério da Educação para a compra de produtos da agricultura familiar para a alimentação escolar. Nesses encontros, abordou a forma como os usuários poderiam se organizar para participar do edital de compras da Prefeitura. Isso denota que o profissional, ao abordar o tema do trabalho e da renda como parte da saúde dos sujeitos e estar atento às suas singularidades, realiza uma prática que vai na contramão da medicalização do cuidado.

O trabalho com a terra, para as pessoas do rural, é, hoje, uma das formas encontradas para fazer frente à exclusão econômica e social. Ainda que permeado por valores externos ligados ao mercado e ao capital, o trabalho na agricultura familiar continua a promover as relações internas capazes de veicular valores camponeses, como já comentado, de prestígio, liberdade e reciprocidade. Trabalhar na terra, mesmo que pouca, tem possibilitado às famílias existir em seus valores, manter-se no campo e incluídos em uma sociedade em que é preciso ter um dinheirinho a mais para sobreviver e ser alguém, como disse Tulipa, agricultora, uma de nossas interlocutoras.

Em entrevista com um servidor da Secretaria de Assistência Social do município, fica explícito o quanto o trabalho com a terra que produz alimentos (e os valores da família) é importante. O interlocutor relata que, em contato com os usuários do SUS, a fim de identificar possíveis casos de insegurança alimentar na localidade, uma pessoa com conhecimento do grupo como um todo lhe havia dito que lá ninguém tem problema desse tipo. Ou seja, lá ninguém seria passível de ser assistido para ter alimento. Nessa perspectiva, não ter condições de assegurar as necessidades com o próprio trabalho e receber, 
assim, assistência de fora/do governo, por si só, já degradaria, desonraria a comunidade. E, de fato, não observamos registros de que na localidade rural estudada, sejam demandadas ações públicas em relação à segurança alimentar e nutricional. Com isso, percebe-se que se alimentar é também uma forma de marcar identidades: a comida fala da família e de valores compartilhados por todos da comunidade (MENASCHE, 2007). Com a comida e o trabalho, seja produzindo diretamente o alimento ou a renda para adquiri-lo, vêm junto o orgulho, a honra e o prestígio que os (re) classificam.

Por último, interessa discutir a terceira forma da mediação produtora de saúde: a do reconhecimento do usuário pela solidariedade. A ação de produção de saúde, de que trataremos e que aparece como solidariedade, se traduz em atitudes que levaram em consideração as necessidades dos adoecidos e se baseiam num interesse afetivo pelo outro, como discute Honneth (2003). Um interesse pelo outro na sua diferença, mas que é, na verdade, um interesse pelo vínculo, pelo bem comum.

Foram relatados por usuários encontros em que o outro da relação, o profissional, agiu de forma solidária com vistas aos mesmos objetivos dele, de minimizar sofrimentos, levando em consideração (sem estigmatizar) características da identidade coletiva do adoecido rural.

Para exemplificar tal constatação, trazemos para a discussão o relato de Lírio, agricultor, e sua esposa sobre a experiência de adoecimento de um dos seus filhos. O menino sofre de problemas respiratórios e precisa fazer uso contínuo de medicamentos, na época não disponíveis pelo sistema de saúde público.

Quando perguntamos ao casal o que lhes ajudou a enfrentar o adoecimento do filho, eles dizem que foi o fato de terem encontrado um médico do SUS que "entendesse desse tipo de coisa". Porém, apreendemos que o "entender" do médico a que Lírio se refere vai para além do caso clínico, ou seja, da doença propriamente dita. Para nosso interlocutor, o médico, além de fazer o devido diagnóstico e prescrever tratamento, compreendeu as dificuldades dele para acessar os remédios e se deixou solidarizar tanto por sua preocupação em não conseguir cumprir com os compromissos com o tratamento e/ou com o profissional, quanto por seu desconhecimento sobre como buscar seus direitos ele (o profissional médico) lhe "estendeu a mão": 
Lírio: [...] Olha doutora, estou perdendo meu tempo. [...] Eu não consigo remédio, se

a senhora está me receitando só remédio e eu não tenho como pagar então, não vou vir mais aqui. [...] Aí ela me disse: - Não, então espera aí. Ela escreveu bem escrito num papel, ela tinha um atestado bem feito, né? E aí sim, aí se encaminhou [...] Conseguimos tanto no fórum como também conseguimos encostar ele.

Pesquisadora: E demorou para conseguir ou foi rápido o encaminhamento?

Lírio: Não, depois que encaminhamos, que ela me ajudou, é porque a gente é meio grosso que vou te dizer uma coisa mesmo, né? Da outra vez eu disse: - Está doutora então não precisa vir mais aqui. Aí, ela virou e disse, deu uma risada bem amiga e disse: - Não meu filho, tu vais vir sempre aqui, eu vou te ajudar. E é difícil ver uma pessoa querida assim que estenda a mão para a gente [...] aí ficamos envolvidos ali, ela conosco, sabendo todos os problemas.

Nesse relato, se pode verificar a mediação produtora de saúde se expressando na atitude solidária do profissional, que age reconhecendo o modo de ser do nosso interlocutor com sua dificuldade para fazer o tratamento e, ao mesmo tempo, coragem e confiança em colocar na mesa os seus limites de compreensão da lógica do SUS. Na relação de cuidado aí estabelecida, o profissional propicia ao usuário sentir-se valorizado, mesmo com todos seus "problemas". Este, por sua vez reconhece o valor do profissional, continua no ciclo da dádiva, permanecendo "ali envolvido" no tratamento e na relação.

Poder cumprir com os compromissos sociais é um dos valores levados a sério pela gente do rural investigado. É com base nesses compromissos, nas relações que são por eles sedimentadas, que o grupo produz também sua identidade. Assim, o outro da relação e a confiança que nele se estabelece aparecem como sendo imprescindíveis para a vida e saúde das pessoas, algo que está na sua essência.

Quanto aos profissionais, quando os observamos em todas as formas de mediação, afetando e se deixando afetar pela presença e valores do adoecido rural, foi possível perceber a demonstração de estarem agindo de acordo com algo que a eles foi confiado: atuar no zelo pela saúde das pessoas. Ao reconhecerem os usuários, os profissionais também recebem o reconhecimento de seu esforço e ambos se mantêm comprometidos com o cuidado e com os vínculos. Ouvimos relatos, tanto de adoecidos quanto de profissionais, de presentes que simbolizam o rural (alimentos produzidos com a força do trabalho da família) e que são dados pelos usuários como forma de agradecimento aos profissionais e de expressão de uma relação produtora de saúde. 
O exercício de mediação produtora de saúde no cotidiano não é uma atitude simples de ser assumida pelos profissionais, visto que demanda uma postura diferenciada, exige a parceria do usuário e o olhar sensível dos profissionais às demandas em saúde e às particularidades da vida no rural. Um dos principais desafios à prática de mediação em saúde no rural refere-se aos estigmas e naturalizações que a sociedade como um todo atribui a esse espaço e ao modo de viver da sua gente. $\mathrm{O}$ estigma em relação ao rural, aqui compreendido em Goffman (2008), é estabelecido em interaçôes, justamente em situações em que "um indivíduo que poderia ter sido facilmente percebido na relação social cotidiana possui um traço que pode se impor à atenção [...] destruindo a possibilidade de atenção para outros atributos seus" (p. 14).

Isso significa que, se a população rural não é reconhecida em suas especificidades e é tida como isolada, sem conhecimento ou algo do tipo, há reflexos disso na ação profissional. De um lado, ao acentuar gradativamente as diferenças entre o "nós" e "os outros", os profissionais podem agir culpabilizando, aumentando o sofrimento do usuário e sendo pouco receptivos ao vivido no rural. De outro lado, pode ocorrer que o profissional, ao não reconhecer o potencial de cuidado que há no reconhecimento dos valores que marcam as identidades rurais, sinta-se impotente para lidar com as situações do rural, resignando-se e sofrendo com isso (CAMPOS, 2005).

No entanto, cabe assinalar que há momentos em que as hegemonias como a do urbano sobre o rural, assim como a do saber biomédico sobre os demais, passam por processos de revisão. A fala a seguir é bastante ilustrativa do quanto o cruzamento entre saberes, desejos e demandas é complexo, mas passível de negociações. Um profissional nutricionista que trabalha, no urbano, com atividades de grupo com a população rural relata:

[...] eu me estresso bastante. Porque, às vezes, eu peso as crianças assim e elas vão tomando refrigerante, comendo salgadinhos, sabe?, [...] aí eu falo com as gurias, aí as gurias me dizem assim, que eles já são daquele jeito. Que eu não sou daqui, quando eu entrei também foi uma realidade que me chocou bastante?![...] Eu estava nua e crua, e aí as gurias me disseram assim que como eles demoram para vir na cidade, quando eles vêm, também eles querem fazer um agrado para a criança. 
Na mediação, ao acolher a demanda do usuário, ao liberar o gesso do instituído e das hegemonias, o profissional assume responsabilidades sobre aquilo com que vier (ou não) a se comprometer. Isso, por sua vez, exige ter autonomia frente à gestão, inventividade e aceitar alimentar a parceria com um usuário que tem uma identidade rural que ele, profissional, muitas vezes, desconhece e que reflete na forma das pessoas construírem seu adoecimento e o cuidado de si; cuidado esse pensado enquanto formas de vivenciar o processo saúde/doença que são singulares e podem ser permeadas de autonomia e protagonismo.

\section{Considerações finais}

Nas leituras que fizemos das diferentes experiências de mediação, apontamos para ações realizadas por profissionais que consideramos serem mediadores na produção da saúde integral. Na forma de vínculos mais afetivos, que respeitam os direitos e valorizam as diferenças do outro, os profissionais foram capazes de produzir, em diferentes âmbitos do SUS, uma atenção em saúde mais reconhecedora tanto da integridade do usuário rural quanto da importância do profissional enquanto mediador das políticas públicas. Essas experiências alimentam a urgência de se identificar e reconhecer a ação desses mediadores considerando seu papel de potencializar a acessibilidade do usuário no sistema ao inovar frente às dificuldades na relação Estado/usuário.

Ao fazer circular os bens com alcance não só biomédico, mas que, com um fundo técnico, também carreguem consigo aspectos democráticos, afetivos e éticos, acredita-se que o mediador, na sua mediação, possa contribuir para se avançar em termos de saúde, com a cidadania e até mesmo com o sucesso dos serviços locais e do Estado de forma mais ampla.

Além disso, percebe-se que os bens de saúde postos em circulação pela mediação dos profissionais não se resumem à materialidade (medicamentos, exames etc.). Ao serem carregados de um espírito, os bens são capazes de produzir saúde quando se revestem de afeto, cidadania e solidariedade. Ou seja, ao serem doações de reconhecimento, são capazes de respeitar a existência coletiva/ individual e a integridade do adoecido nos seus valores de camponeses do lugar.

Para finalizar, gostaríamos de problematizar que a(s) ruralidade(s) se mostra(m) ímpar(es) para que as ações em saúde tenham êxito. Mesmo que haja boas intenções ao facilitar o acesso dessa população ao sistema de saúde, sem a 
devida desnaturalização desses espaços, das vidas e valores que o constituem, possivelmente o profissional de saúde, ao doar os bens das políticas, irá reproduzir estigmas e modos de fazer disciplinadores que pouco contribuem para os avanços no campo da saúde rural. ${ }^{1}$

\section{Referências}

ALMEIDA-FILHO, N. Desigualdades em saúde segundo condiçōes de vida: análise da produção científica na América Latina e Caribe e bibliografia anotada. Washington, DC: Organização Pan-Americana de Saúde, 1999.

ALVES, V. S. Um modelo de educação em saúde para o Programa Saúde da Família: pela integralidade da atenção e reorientação do modelo assistencial. Interface - Comunic, Saúde, Educ., v. 9, n. 16, p. 39-52, 2004.

AYRES, J. R. C. M. Cuidado e reconstrução das práticas de Saúde, Interface - Comunic., Saúde, Educ., v. 8, n. 14, p. 73-92, set.2003-fev.2004.

BARROS, M.B.A et al . Desigualdades sociais na prevalência de doenças crônicas no Brasil, PNAD-2003. Ciênc. saúde coletiva, Rio de Janeiro, v. 11, n. 4, p. 911-926, dez. 2006.

BRASIL. Lei Complementar no 11, de 25 de maio de 1971. Institui o Programa de Assistência ao Trabalhador Rural, e dá outras providências. Diário Oficial [da] República Federativa do Brasil. Brasília, 26 maio 1971; republicado em 05 ago. 1971, 24 nov. 1971, 25 nov. 1971 e retificado em 26 nov. 1971.

. Ministério da Saúde. Politica Nacional de Atenção Básica. Brasília: Ministério da Saúde, 2012. 114 p. Disponível em: <http://189.28.128.100/dab/docs/publicacoes/geral/ pnab.pdf>. Acesso em: 31 ago. 2013.

BURILLE, A.; GERHARDT, T. E. Doenças crônicas, problemas crônicos: encontros e desencontros com os serviços de saúde em itinerários terapêuticos de homens rurais. Saúde soc., São Paulo, v. 23, n. 2, p. 664-676, jun. 2014.

CAILLÉ, A. Antropologia do dom: o terceiro paradigma. Petrópolis: Vozes, 2002.

CAMPOS, R.O. O encontro trabalhador-usuário na atenção à saúde: uma contribuição da narrativa psicanalítica ao tema do sujeito na saúde coletiva. Ciênc. saúde coletiva, Rio de Janeiro, v. 10, n. 3, p. 573-583, jul./set. 2005.

CHANIAL, P. Justice, don et association: la délicate essence de la démocratie. Paris: La Découverte/MAUSS, 2001.

COSTA, M. C. Violência contra mulheres rurais, agendas públicas municipais e práticas profissionais de saúde: o visível e o invisível na inconsciência do óbvio. 2012. 317 f. Tese (Doutorado em Enfermagem) - Escola de Enfermagem, Universidade Federal do Rio Grande do Sul, Rio Grande do Sul, Porto Alegre, 2012. 
ESCOREL, S.; TEIXEIRA, L. A. História das Políticas de Saúde no Brasil de 1822 a 1963: do império ao desenvolvimentismo populista. In: GIOVANELLA, L. et al. (Org.). Políticas e sistema de saúde no Brasil. Rio de Janeiro: Editora Fiocruz, 2008. p. 333-384.

GALVÃO, E. L., et al. Análise da distribuição geográfica dos serviços de saúde no Vale do Jequitinhonha, Minas Gerais. Hygeia, Uberlândia, v. 11, n. 20, p 32-44, jun. 2015.

GERHARDT, T. E.; LOPES, M. J. M. (Org.). O rural e a saúde: compartilhando teoria e método. Porto Alegre: Editora da UFRGS, 2015. 208 p.

GODBOUT, J. T. O espírito da dádiva. Lisboa: Instituto Piaget, 1997.

GOFFMAN, E. Estigma: notas sobre a manipulação da identidade deteriorada. Rio de Janeiro: LTC, 2008.

INSTITUTO BRASILEIRO DE GEOGRAFIA E ESTATÍsTICA. Sinopse do Senso Demográfico de 2010. Rio de Janeiro: IBGE, 2011.

HONNETH, A. Luta por reconhecimento: a gramática moral dos conflitos sociais. São Paulo: Ed. 34, 2003.

LACERDA, A. Redes de apoio social no sistema da dádiva: um novo olhar sobre a integralidade do cuidado no cotidiano de trabalho do agente comunitário de saúde. 2010. Tese (Doutorado) - Escola Nacional de Saúde Pública Sérgio Arouca, Fundação Oswaldo Cruz, Rio de Janeiro, 2010.

LERRY, J. P. Debatendo o capítulo ambiente, espaço, território e o campo da saúde: a agricultura. In: MINAYO, M. C. S.; MIRANDA, A. C. (Org.). Saúde e ambiente sustentável: estreitando nós. Rio de Janeiro: Fiocruz, 2002.

MARTINS, P. H. Dom do reconhecimento e saúde: elementos para entender o cuidado como mediação. In: PINHEIRO, R.; MARTINS, P. H. (Org.). Usuários, redes sociais, mediaçôes e integralidade em saúde. Rio de Janeiro: Cepesc, 2011. p. 39-50.

. A sociologia de Marcel Mauss: Dádiva, simbolismo e associação. Rev. Crit. Ciências Sociais, 73, p.45-66, dez. 2005.

- Usuários, redes de mediação e associações públicas híbridas em saúde. In:

PINHEIRO, R.; MATTOS, R. A. (Org.). Cuidar do cuidado: responsabilidades com a integralidade das ações de saúde. Rio de Janeiro: Cepesc, 2008. p 356-81.

MAUSS, M. Ensaio sobre a dádiva: forma e razão da troca nas sociedades arcaicas. In: Sociologia e antropologia. São Paulo: Cosac \& Naify, 2003.

MENASCHE, R. (Org.). A agricultura familiar à mesa: saberes e práticas da alimentação no Vale do Taquari. Porto Alegre: Ed. da UFRGS, 2007.

MINAYO, M. C. S. O desafio do conhecimento: pesquisa qualitativa em saúde. $11^{\text {a }}$ ed. São Paulo: Hucitec, 2008. 
OLIVEIRA, E. M. et al. Determinantes sócio-históricos do cuidado na Estratégia Saúde da Família: a perspectiva de usuários da área rural. Saúde e Sociedade, São Paulo, v. 24, n. 3, p. 901-913, 2015.

PINHEIRO, R.; MARTINS, P. H. (Org.). Usuários, redes sociais, mediações e integralidade em saúde. Rio de Janeiro: Cepesc, 2011.

PERETTO, M. et al. Gravidez na adolescência em oito municípios do RS: perfil de ocorrência e rede de serviços. Rev. Eletr. Enf., v. 13, n. 4, p. 721-9, 2011.

RIQUINHO, D. L. A outra face dos determinantes sociais de saúde: Subjetividades na construção do cotidiano individual e coletivo em uma comunidade rural. 211 f. 2009. Dissertação (Mestrado) - Escola de Enfermagem, Universidade Federal do Rio Grande do Sul, Porto Alegre, 2009.

RIQUINHO, D. L.; GERHARDT, T. E. Doença e incapacidade: dimensões subjetivas e identidade social do trabalhador rural. Saúde soc., São Paulo, v. 19, n. 2, p. 320-332, jun. 2010. RIQUINHO, D. L.; HENNINGTON, E. A. Cultivo do tabaco no sul do Brasil: doença da folha verde e outros agravos à saúde. Ciência \& Saúde Coletiva, v.9, n.12, p.4797-4808, 2014. RUIZ, E. N. F.; GERHARDT, T. E. Políticas públicas no meio rural: visibilidade e participação social como perspectivas de cidadania solidária e saúde. Physis: Revista de Saúde Coletiva, Rio de Janeiro, v. 22, n. 3, p. 1191-1209, 2012.

RUIZ, E. N. F. Relaçôes sociais nas situaçôes de adoecimento crônico no rural: expressôes de cuidado e de sofrimento na perspectiva da dádiva. Faculdade de Ciências Econômicas. 2013. 212f. Tese (Doutorado em Desenvolvimento Rural) - Faculdade de Ciências Econômicas, Universidade Federal do Rio Grande do Sul, Rio Grande do Sul, Porto Alegre, 2013.

SANTOS, D.L.; GERHARDT, T.E. Desigualdades sociais e saúde no Brasil: produção científica no contexto do Sistema Único de Saúde. Rev. Gaúcha Enferm., Porto Alegre, v. 29, n. 1, p. 129-136, mar. 2008.

SANTOS, V. C. F. Articulação de açôes e práticas em saúde: a mediação do cuidado na rede assistencial de São Lourenço do Sul/RS. 170f. Dissertação (Mestrado em Enfermagem) Escola de Enfermagem. Universidade Federal do Rio Grande do Sul, Rio Grande do Sul, Porto Alegre, 2013.

SANTOS, V. C. F.; GERHARDT, T. E. A mediação em saúde: espaços e açôes de profissionais na rede de atenção à população rural. Saúde soc., São Paulo, v. 24, n. 4, p. 1164-1179, Dec. 2015.

SOBREIRA, A. G. P.; ADISSI P. J. Agrotóxicos: falsas premissas e debates. Ciência \& Saúde Coletiva, v. 8, n. 4, p. 985-90, 2003.

TOVAR-CUEVAS, L. M.; ARRIVILLAGA-QUINTERO, M. Estado del arte de la investigación en acceso a los servicios de salud en Colombia, 2000-2013: revisión sistemática crítica. Rev. Gerenc. Polit. Salud, Bogotá, v. 13, n. 27, Dec. 2014. 
UCHOA, A. C. et al . Avaliação da satisfação do usuário do Programa de Saúde da Família

na zona rural de dois pequenos municípios do Rio Grande do Norte. Physis: Revista de Saúde Coletiva. Rio de Janeiro, v. 21, n. 3, p. 1061-1076, 2011.

VEIGA, J. E. Destinos da ruralidade no processo de globalização. Estudos Avançados, n.51, p 51-67, mai/ago. 2004.

WANDERLEY, M. N. B. A emergência de uma nova ruralidade nas sociedades modernas avançadas - o "rural" como espaço singular e ator coletivo. Estudos Sociedade e Agricultura, v. 15 , p. $87-145$, out. 2000 .

. Olhares sobre o "rural" brasileiro. Raizes, Campina Grande, v. 23, n. 1-2, p. 82-98, jan./dez. 2004.

O campesinato brasileiro: uma história de resistência. Rev. Econ. Sociol. Rural, Brasília, v. 52, supl. 1, p. 25-44, 2014 .

. O mundo rural como um espaço de vida: reflexōes sobre a propriedade da terra, da agricultura familiar e ruralidade. Porto Alegre: Editora da UFRGS, 2009.

WOORTMANN, K. Com parentes não se neguceia: o campesinato como ordem moral. An Antropol., Brasília, v. 87, p. 11-73. 1990.

\section{Nota}

${ }^{1}$ E. N. F. Ruiz concebeu o projeto de pesquisa, trabalhou na coleta de dados, na interpretação dos resultados, na redação e na revisão do artigo. V. F. dos Santos concebeu o projeto de pesquisa, trabalhou na coleta de dados, na interpretação dos resultados, na redação e na revisão do artigo. T. E. Gerhardt concebeu o projeto de pesquisa, trabalhou na interpretação dos resultados, na redação e na revisão do artigo. 


\section{Abstract}

\section{Mediations in health care under the perspective of the Theory of Gift: highlights of the health of a rural population}

The study analyzes, from the perspective of Mauss' Theory of Gift, the implications of mediation between users and the policies carried out by health professionals. The study was conducted under a qualitative approach, with data produced from interviews and participatory observation with professionals, users and managers of SUS in two municipalities of Rio Grande do Sul state, Brazil. Data analysis used a thematic analysis approach. It was found that stigma related to the way of life in the rural interferes in how professionals work with users, sometimes making their needs reduced to offering an assistance technical repertoire and professional supervision that creates greater difficulties to health services access. Also, it was found that health mediation, analyzed from the gifts circulation, proved to be a chance of professionals to exceed the biomedical limits, establish more symmetrical relationships with the users, and exercise the ability to perform comprehensive changes in the world of rural life. These elements have potential to enhance the movement of materiality and immaterialities, which have the power to produce affection, citizenship and solidarity.

> Key words: rural population; mediation in health; gift. 